April - 2004

\title{
Book Review - The Future of Learning: From eLearning to mLearning
}

Editor: Keegan, D. (2002). The Future of Learning: From eLearning to mLearning. 172 pages, online. ZIFF Papiere 119, FernUniversitat - Hagen. ISSN: 1435 9340. Available at no cost online at: http://www.fernuni-hagen.d/ZIFF/mlearn.htm

Reviewed by: Murugan Krishnapillai, The University of the West Indies, Barbados

This e-book is a report of a study, which is supported by the European Union Leonardo da Vinci programme, about the potential of wireless technologies for teaching/learning at a distance. Despite its focus on the wireless e-learning scenario in Europe, this report does bring to the fore the pedagogic feasibility of using wireless technologies in distance teaching/learning contexts beyond Europe. Of the 10 chapters that form this report, the first three attempt to provide theoretical scaffolding to the discussion of mobile learning in Chapter 4. Chapters 5 to 8 contain a compendious account and a tenuous analysis of four wireless devices used for creating mobile learning contexts. Chapter 9 describes student perceptions of and experience with mobile learning. Building on the foregoing discussion, Chapter 10 urges Europe to take up the leadership role, because it forecasts the inevitability of adapting to mobile learning environments, consequent on the growth of wireless technologies and, indeed, a wireless future.

This 172-page report defines distance learning (“d-learning”) as essentially learning through print, e-learning as electronic learning in wired environments, and m-learning as wireless elearning. This report also claims "to provide an analytical and theoretical background to the field of education and training provision known as mobile learning...[a] provision of education and training courses on wireless devices...[and] sees the provision of education at a distance as a continuum and traces an evolution from d-learning (distance learning) to e-learning (electronic learning) to m-learning (mobile learning) ...” (p. 6).

Chapter 1 (p. 8 -17), 'The future of learning,' describes the close nexus between technologies and educational environments, and in that context outlines how industrial and electronic revolutions have paved the way for traditional distance education, the mainstays of which is the print medium and electronic learning (e-learning), respectively. This Chapter describes how the evolution of mobile technologies "will change the distance student from a citizen who chooses not to go to college, to a person who not only chooses not to go to college, but is moving at a distance from the college" (p. 11). The emerging challenge, as a consequence, is to build appropriate learning systems for "wireless computing and telephony" in the same way "as eLearning has provided for wired computing and telephony" (p. 16).

Chapter 2 (p. 18 - 30) entitled 'From d-Learning to e-Learning' describes distance education, and discusses its two forms and traces its history. The author uses the expression "d-Learning" to refer to both distance learning (p. 18) and teaching at a distance (p. 19). He then makes a 
distinction between individual-based and group-based distance education, seen respectively as the result of the Industrial and Electronic Revolutions. Finer distinctions between these two are also made: while "pre-prepared" (p. 23) and "without pre-prepared" (p. 25) materials are used for individual-based distance training, the group-based distance education is for both full-time and part-time students. Group-based distance learning is seen as linking "the teacher and the learners in several geographic locations by simultaneous audio, video, or satellite links, to a network of remote classrooms" (p. 20). The author points out that "Group-based d-Learning systems are referred to as 'distance learning' in the United States, while individual-based systems are referred to as 'distance education' in Europe" (p. 20). He further adds, "The distinctions between the American distance learning based largely on synchronous communication technologies and the European distance education based in the main on asynchronous technologies is important because it influences development in both e-Learning and m-Learning” (p. 26).

Chapter 3 (p. 31 - 43) 'From e-Learning to m-Learning' moves forward from where Chapter 2 left off, by discussing the status of e-learning. The author defines it as "the award of nationally and internationally recognised university degrees, college diplomas and training certificates to students who spend all or much of their study programme sitting in front of a computer” (p. 15). Referring to the TeleEducation directory (http://courses.telecampus.edu), a worthwhile reference, indeed, which contains a list of a number of online courses, the author remarks, "there is a growing acceptance of Web components of courses contributing to the award of a degree” (p. 36), though "The status of e-Learning is high in corporate training" (p. 36). He also points out, "the growing availability of commercially available Learning Management Systems (LMSs)” (p. 36) attests to this trend.

Chapter 4 (p. 43 - 84) 'm-Learning initiatives today,' presents 30 predominantly European initiatives (21 mobile learning trials, two portals, three conferences, one workshop, and three articles on the theoretical constructs of mobile learning) "to give the background and context to the sector and demonstrate the growing importance of m-Learning as a field of educational research and endeavour" (p. 43). Contrary to the author's claim that: "30 mobile learning initiatives today are presented and analysed" (p. 43), this Chapter is a collection of the descriptions of m-learning initiatives without any meaningful analysis. It presents three theoretical constructs of m-learning, one each from J. Sarida ('What are limits of academic teaching? - In search of the opportunities of mobile learning'), K. Nyiri ('Towards a philosophy of m-learning'), and G. Ring ('m-Learning case study with Nokia and INSCAD).

Chapter 5 (p. 85 - 86) 'm-Learning on the screen phone', the shortest chapter in the report, features the short life cycle of screen phones, because "It was never likely that students would purchase a device like the screen phone merely for the purpose of study" (p. 86). This reflects the author's earlier statement: "If there is a rule about the choice of technology for distance training, it is that technologies that are available to citizens may succeed" (p.11), and which is true. However, the author is quick to point out that, Ericsson's decision to suspend the production of screen phones "does not in any way weaken the field of mobile learning. ..” (p. 86).

Chapter 6 (p. 87 - 113) 'm-Learning on personal digital assistants (Compaq iPAQ)', seems to be a critical one, given the focus of the report and that it contains a description of Compaq iPAQ 3650 Pocket PC, and a discussion based on the lessons-learned article written by Fagerberg, et al. on the design of a learning environment and its delivery "carried out at NKI distance education during the year 2001 of the EU Leonardo Project” (p. 88). The chapter describes how a Webbased course was adapted and designed to suit the purpose, the options thought of for its delivery (as content made available on a commercial server for online access via mobile phone; download- 
on-demand as zipped HTML files, and as ready-to-use Microsoft Reader files), and the reasons for the choice of MS Reader with ClearType.

Chapter 7 (p. 114 - 119) 'm-Learning on the smart phone (Ericsson R 380)' contains a

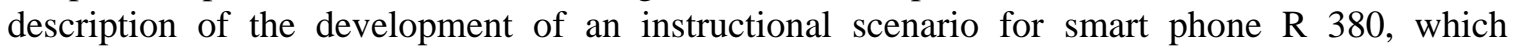
combines the roles of a mobile phone, personal digital assistant (PDA) and mobile Internet browser (WAP browser). The discussion of the pedagogical considerations to be addressed for the creation of learning environments suitable for smart phone is partly based on an article by Almeida ('The advantages and disadvantages of using WAP in developing an m-Learning course.')

Based on the article by Almeida referred to above, Chapter 8 (p. 120 - 125) 'm-Learning on the WAP phone (Ericsson R 520)' describes the development of courseware for R 520. As reported by the author, Almeida claims, "The main limitations of WAP today are related to the devices used and the mobile networks" (p. 122). For example, owing to narrow bandwidth for WAP network, large amounts of data, especially graphics and animations, are not recommended in mobile learning environments.

Chapter 9 (p. 126 - 166) 'Student use of m-Learning' describes "the experiences of mobile learning with real students in real learning situations" (p. 126). One such experience was an exercise in which 43 students (29 in Ireland and 14 in Norway) participated. Some of the criteria used to collect the feedback included student friendliness, didactic efficiency, technical feasibility, cost effectiveness, downloading and synchronising (to PDAs) speed, reading and studying/note taking ease on the PDA, interaction among tutors and students, etc.

In Chapter 10 (p. 166 - 169), 'Conclusion,' Keegan observes that mobile learning is firmly situated in the future of learning (p. 166) and advances two reasons to support mobile learning: the need for telecommunications industry to develop revenue-generating applications and the need to safeguard from the USA packaged learning environments, in which it leads. To complement the Ericsson and Nokia lead in wireless technologies, the author remarks that Europe must develop learning applications for wireless devices and take up the leadership role it enjoyed during the open education era. In any case, as Kristiansen remarks the challenge for the development of mobile learning "lies more within pedagogical and organisational aspects than with technological ones” (p. 55).

It is good to see that many titles listed under Bibliography (p. 170 -172) have electronic versions that are available online, which is indeed helpful to further satiate one's curiosity or interest in the field under discussion.

What seems to underlie the report is the anxiety, or perhaps the conviction that advancement of mobile learning will require a paradigm shift in learning. This interpretation merits debate. However, the point the report makes regarding the need for evolving a more robust instructional systems including design aspects, consequent to the inadequacy of present systems suitable for wired environments, is of critical importance. As much as the predominantly print-based traditional distance education provision is to be tailored to suit its electronic cousin, so is the need for trimming the online version available in wired environments to suit the wireless ones.

An account of the EU Leonardo da Vinci programme would have helped the readers place the report in the overall context. Except for a few sporadic references (of course, including a URL), 
the report does not contain information about that programme. It is also difficult to decipher why this report, in its presumably unedited and draft form, was posted on the Web. Had this been edited (content, language and copy), irritating errors in presentation including inconsistent descriptive statistics (p. 8, 11, 13), unabashed repetitions (p. 12, 15, 25, 34, etc.), language slips (spelling mistakes and wrong syntax, etc., pagination/layout, wrong placement of subheadings, etc.), would have been averted and could have made the reading interesting. The presentation is so woolly that it is difficult to say whether some of the statements made in the report belong to the author or others. Is there a lesson for those of us in the business of distance education, be it traditional or new technology-mediated/assisted? Despite content of remarkable quality, ineffective presentation can and will distract a reader, if the presentation is ineffective!

Furthermore, instead of contributing to clarity of the definition/ description of distance education (as did Keegan's now classic list of distance education characteristics), the presentation in this report is convoluted and confusing, to say the least. Linked to this definition fiasco is the issue the author raises as "an analyst," rather than a stakeholder who chooses "to champion distance learning or criticize campus universities” (p. 18): whether "institutional learning is essentially linked to these privileged places [schools and colleges] for institutional learning created by society” (p. 19). The point is learning (as we use it here) is indeed linked to institutions, whether the provision of education is place-bound or electronic. For example, in the context of the legal description of distance education, the author himself maintains "A student either contracts with a conventional school, college, or university to attend that institution, to join its community of students and to receive its certificate or diploma or degree. Whether this student receives the qualification by attending classes or lectures, working in the library, or the laboratory, or at a computer screen, or on the World Wide Web, depends on the legal requirements stipulated in the statutes of the institution” (p. 29).

In addition, going by the author's stance that "web-based education is best regarded as a subset of distance education" (p. 29), one may tend to believe that he considers m-learning along the same lines. But, he claims “. . . in spite of the arrival of eLearning, distance learning had established itself as a valid field of educational endeavour complementary to and side by side with conventional provision ....” (p. 30). This is as much contradictory as confusing. In addition, both distance learning and distance education are used synonymously as also learning, training, and education. But no reference is made in the report to this effect.

The report may be seen an account of the evolution of teaching/learning at a distance, from distance learning through electronic learning to mobile learning corresponding to the industrial, electronics and mobile revolutions. "Far from seeing conflict in the tensions ... the vision here is of the richness and choice that confronts the learner in the twenty-first century for both education and training ... .with the elimination of wiring and fixed installations for many applications, and the future blessing of voice input into machines.” (p.15). To this extent, the report clearly captures the possibilities of using wireless tools for providing education at a distance, but it chooses to ignore the issue of the digital divide. The author says, "At the time of writing we have only seen the beginning of the wireless information society" and "The World Wide Web and the Internet are not enough . . . wireless access independent of location and Internet services everywhere is the requirement. The air interface is replacing the wire interface.” (p. 11).

The overview of the report, which for reasons unknown, is given at the end of Chapter 1 , proclaims "This book seeks to present mobile learning within the context of distance learning (dLearning) and electronic learning (e-Learning)" (p. 17) which the author considers "the state of the art in distance learning at the time of writing" (p. 15). If this is so, how come mobile learning 
marks an evolutionary stage, a next stage in e-learning as presented in page 9: "The evolution in education and training at a distance can be characterised as a move form d-Learning (distance learning) to e-Learning (electronic learning) to m-Learning (mobile learning). These three stages of development. . ." It indeed is confusing. Based on the forecast about the access solely of mobile telephones, it has been pointed out: "There has never been a technology that has penetrated the world with the depth and rapidity of mobile telephony" (p.12) and suggested that the future lies in mobile learning. But what are the statistics available as regards screen phones, PDAs (Personal Digital Assistants), smart phones and WAP telephones, which the report deals with as mobile learning devices in Chapters 5 to 8? Are then mobile phones considered the primary device for mobile learning? If they are, then the argument about mobile learning will fall flat. All that one can then highlight is the possible support role of mobile phones for distance learning/teaching transactions.

The report would have been less distractive and cumbersome and, indeed, more forceful and revealing, had it focused only on the possibilities and promises the myriad wireless technologies hold for the conduct of teaching/learning transactions. I am at a loss to find why in the first instance the author laboured in vain to provide a theoretical scaffolding, when it is not available or not needed to the introduction of wireless (and therefore mobile, according to the author) technologies for distance teaching/learning. As Dichanz rightly observes, “ . . . e-learning seems to be used to convince users that some supernatural things happens with your brain when you place yourself in front of a computer screen. This miracle is unlikely to happen, as "learning in the real world is mainly hard work" and so learning "cannot be 'electronic"” and "learning cannot be mobile. Learners are probably more and more mobile, and they use mobile technology" (p. 90).

In a broad sense, this report demonstrates the influence corporate bodies can have on education in that companies involved in the business of mobile technologies fund research studies involving influential, and perhaps unsuspecting or willing, academics to promote their products under the guise of technology-enhanced learning. Sariola et al. wonder if the term 'm-Learning' 'is a commercial trick to market technology and educational services or if it is an emerging concept that educationalists should take seriously” (p. 91). As education gets increasingly commodified in the emerging trade in services regime of the World Trade Organization (WTO), it perhaps is little surprising that enterprises take upon themselves the task of research and its dissemination to further their interests, and as a consequence leave educational institutions, which hitherto assumed the role of generation, extension and dissemination of new knowledge, at the periphery. Government apathy towards higher education leaves it susceptible or vulnerable to the enterprising baits, lest it has to compete willy-nilly for scarce resources without any guarantee for success.

One may not fully agree with the mobile learning projection, but it is indeed a useful report to understand the growth of mobile technologies and their potential for learning. It is possible that the report will inspire readers/institutions to take up projects on similar lines, experiment with the PDA-based/ assisted learning environments and adjudge their use in various contexts. In any case, as the report is available online, every attempt must be made to access and read it in order to continue the discussion on distance education.

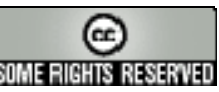

